Florida International University

FIU Digital Commons

Electrical and Computer Engineering Faculty

Publications

College of Engineering and Computing

4-2014

\title{
Optimal Reliability-based Placement of Plug-In Electric Vehicles in Smart Distribution Network
}

Mohammadhadi Amini

Arif I. Sarwat

Follow this and additional works at: https://digitalcommons.fiu.edu/ece_fac

Part of the Electrical and Computer Engineering Commons

This work is brought to you for free and open access by the College of Engineering and Computing at FIU Digital Commons. It has been accepted for inclusion in Electrical and Computer Engineering Faculty Publications by an authorized administrator of FIU Digital Commons. For more information, please contact dcc@fiu.edu. 


\title{
Optimal Reliability-based Placement of Plug-In Electric Vehicles in Smart Distribution Network
}

\author{
Mohammadhadi Amini ${ }^{1}$, Arif I. Sarwat"2 \\ Department of Electrical and Computer Engineering, Florida International University, 10555 W. Flagler St., Miami, \\ FL 33174, USA \\ ${ }^{1}$ mamin006@fiu.edu; *2asarwat@fiu.edu
}

\begin{abstract}
Distributed renewable resources are one of the major technological inclinations that play a pivotal role in the future green power system. In this context, high penetration of Plug-In Electric Vehicles (PIEVs) may bring many challenges for the smart grid. PIEVs' unscheduled utilization will cause technical issues for both generation side and demand side. High penetration of PIEVs may lead to reliability deterioration of smart distribution network. In this paper, firstly a PIEV owner behavior model is introduced. The output of this model is the hourly demand of PIEVs per day. Secondly, a comprehensive reliability-based objective function is proposed to allocate these modeled PIEVs in smart distribution network. Finally, IEEE RBTS bus 2 is used for implementing allocation algorithm utilizing both genetic algorithm and particle swarm optimization.
\end{abstract}

\section{Keywords}

Plug-In Electric Vehicle (PIEV); Reliability-based Objective Function; Smart Distribution Network; Heuristic Optimization

\section{Introduction}

Regarding the ever increasing demand for power generation and limits on current resources only one suggestion can be practical and economical, that is to take advantage of distributed renewable resources (DRRs) and to cut down on reliance on fossil fuels in order to have a more environmental-friendly power grid. Hydroelectric, wind power and photovoltaic in comparison with coal, have shown to have great potentials since they can be near to the place of energy demand. Therefore, these sort of energy resources will require a lot of modern equipment. As standard of life continues to rise, so have consumer expectations and demands for power reliability.Considering the great extent of the grid application of old methods of direct and continuous supervision by staff is not anymore feasible and more optimized solutions should be thought of [1]. In the beginning of the 21st century this concern led to a great movement smart grid (SG) was one of its outcomes.

Smart grid will gradually lead to the development and upgrading of the whole power grid, including electric power generating, transmission, distribution and supplying, that creates a more secure, energy-saving, environmental protection, and economic power systems [2-3]. Figure 1 demonstrates the role of PIEVs as distributed resources in the smart grid framework.

Figure 1 shows the schematic view of the industry drivers of Smart Grid as mentioned in [4]. As shown in this figure the new face of Smart Grid include (a) emphasis on environmental protection, including variable generation (wind, solar, etc.), demand response, and distributed generation, (b) the drive for better asset utilization, including operating closer to the "knee of the curve" while maintaining reliable system operation, and (c) the need for enhanced customer choice[4].

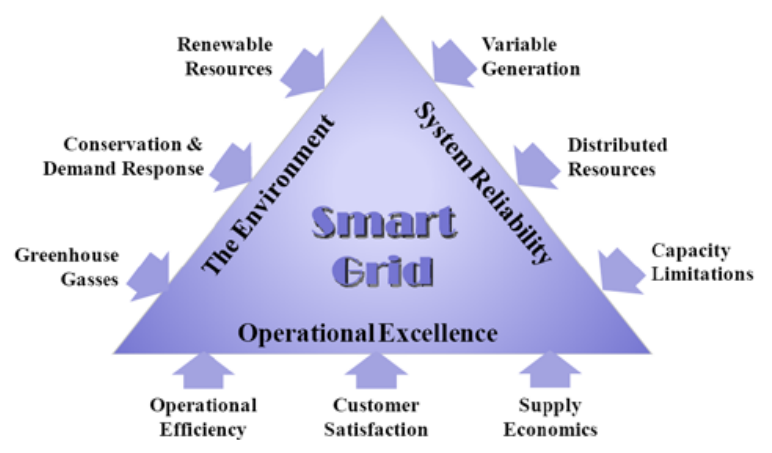

FIG. 1A NOVEL PARADIGMFOR SMART GRID [4]

Another concept which appears in Smart Grid environment is smart home. Gelling depicts the smart home with control center and energy management system as fig 4 . In this home, several mentioned elements of the Smart Grid such as AMI, DG and electric vehicle are considered [5][6]. 


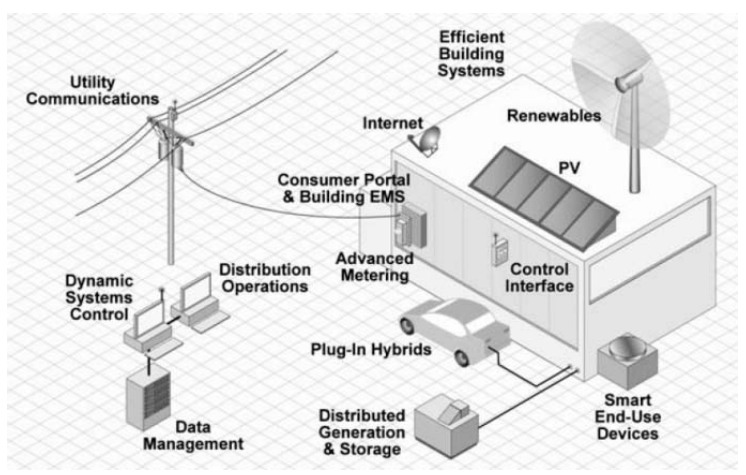

FIG. 2 FUTURE HOMES, ENABLING SMART GRID TECHNOLOGIES [5]

As figure 2 shows, Plug-In Electric Vehicles (PIEVs) are inevitable part of future power system, especially in smart homes. They can serve as storages like the flexible loads [7].

If the EV can inject the stored power to the grid, it is referred to as V2G [8]. Fig.2 depicts a gradual raise in the amount of EVs and the impact of controlled and uncontrolled charging curve at the peak load [9-10]. As shown in this figure, uncontrolled charging deteriorates load curve.

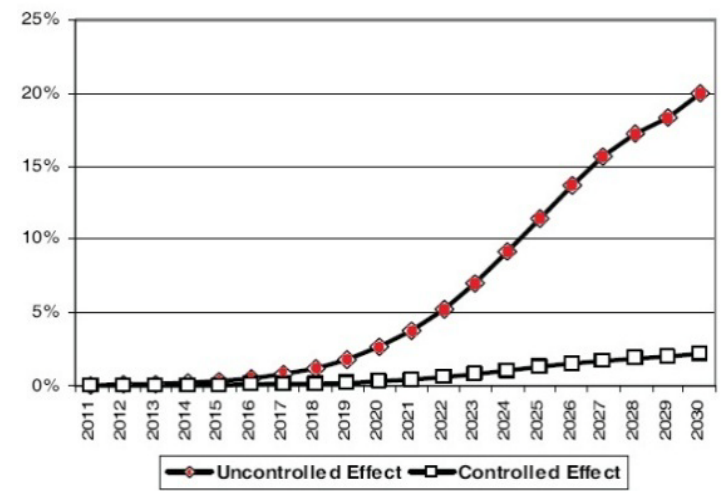

FIG.3 FORECASTING THE PEAK INCREASING DUE TO CONTROLLED AND UNCONTROLLED CHARGING [9]

The rest of this paper is arranged as follows: In the next section, PIEV's customer behaviormodeling is introduced. This model is based on PIEV users' survey. Then, problem formulation is addressed in terms of defining a reliability-based objective function. Next section, is devoted to the optimization methodology. This section will introduce two approaches for optimal allocation of PIEVs. Case study is discussed after introducing two optimization methods and the last section, concludes the paper.

\section{PIEV Owners Behavior Modelling}

There is a comprehensive model which introduced in [11]. For the modeling purpose, an acceptance function is defined. This function is based on four variables: electricity price, fuel price, charging rate (fast or slow) and charging control (controlled or uncontrolled). This function is shown in (1)[11]:

$$
\begin{aligned}
F_{j}\left(t, p_{j}, y\right) & =F_{C E_{j}}\left(t, p_{j}\right)+F_{C F_{j}}(t, y) \\
& +F_{F S P_{j}}(t)+F_{C U P_{j}}(j)
\end{aligned}
$$

where " $t$ " represents different times of day, " $y$ " is an interval in which fuel prices are understood to be fixed and pj represents time intervals each of which of two hour duration, as defined by (2):

$$
p_{j}=[2 j, 2+2 j] \quad ; j \in\{0,1, \ldots, 11\}
$$

$F_{C E_{j}}, F_{C F_{j}}, F_{F S P_{j}}$ and $F_{C U P_{j}}$ show the electricity price, fuel price, fast charging penetration and controlled charging penetration, respectively.

According to the survey of $30 \mathrm{PHEV}$ owners and curve fitting on each of the four factors, coefficients $\sum a_{i} t^{i}$,

$\sum b_{i} t^{i}, \sum c_{i} t^{i}$ and $\sum d_{i} t^{i}$ were extracted.

In order to compare different scenarios and investigating the effect of electricity price on $\mathrm{EV}$ customers' behavior this paper defined a customer acceptance index (CAI ) [11]. This index is shown in the following equation:

$$
\mathrm{CAI}=\frac{\sum_{j=0}^{11}\left[\int_{t=2 j}^{2 j+2} F_{j}\left(t, p_{j}, y\right) d t\right]}{24}
$$

This model is adaptive for customer behavior prediction. Nevertheless, another model should be introduced to evaluate the parking lots charging demand. As the main objective of this paper is reliability evaluation, only the charging rate is counted as variable in this model. Figure 5 demonstrates the charging rate effect on this model output.

\begin{tabular}{c|c} 
TABLE I CHARGING RATES IN A PROPORTION OF BATTERY CAPACITY \\
Charging Mode & Charging Rate \\
\hline Slow Charging & $0.1 \mathrm{BCAP} /$ hour \\
\hline Quick Charging & $0.3 \mathrm{BCAP} /$ hour \\
\hline Fast Charging & $1.0 \mathrm{BCAP} /$ hour
\end{tabular}

\section{Problem Formulation}

In this part, two methods are utilized to allocate the PIEVs in the smart distribution network. Firstly, a reliability-based objective function is introduced for 
the optimization purpose. The proposed objective function can be shaped based on various purposes. The input of proposed objective function is the output of probabilistic PIEV model which is discussed in section II. Furthermore, the characteristic of the smart distribution network which is used for the simulation purposes is another input of optimization process. Objective function of PIEVs placement in a feeder is subject to improve power distribution system reliability satisfying some constraints. Two influential reliability indices are used in order to evaluate the distribution network's reliability; The Customer Average Interruption Duration Index (CAIDI) which is commonly used by power utilities in order to consider the average outage duration that is expectable for customer to experience, and energy not supplied (ENS) are considered [12].

The proposed objective function (OF) illustrated in the following equation, indicates composite reliability index through weighted aggregation of these two indices [13]:

$$
O F=\left(\alpha_{C A I D I} \times \frac{C A I D I}{C A I D I_{T}}\right)+\left(\alpha_{E N S} \times \frac{E N S}{E N S_{T}}\right)
$$

Where $O F$ is a composite reliability index and coefficient $\alpha_{x}>0$ indicates the weight for corresponding reliability index and subscript $T$ indicates the target value of each index. These coefficients are considered to be the same value 0.5, and the objective value of CAIDI and ENS are considered 1.5 hours (based on IEEE Standard 13661998 this index's value is about 1.36 for the North American utilities) and 47, respectively. In the proposed optimization framework, technical issues of power distribution network such as power consumption of PIEVs and voltage constraints are considered.

\section{Optimization Using Particle Swarm Optimization and Genetic Algorithm}

In order to optimize the proposed objective function there are various population-based heuristic methods include genetic algorithms, evolutionary computation, and particle swarm optimization (PSO). Prior research using the genetic-algorithm (GA) and simulatedannealing (SA) techniques has provided effective optimal designs for various apparatuses and systems [14][20]. In this paper the optimization is obtained utilizing both GA and PSO so that the comparison between results from these two optimization methods leads to more accuracy in placement process.
Because of the discrete nature of allocation process, it has numbers of local minimums. To optimize this type of objective function, heuristic algorithms may be effective. In this paper genetic algorithm (GA) is used to minimize the proposed objective function containing two high-flying reliability indices [13]. In this paper fitness function of genetic algorithm and objective function considered to be the same. The chromosomes include binary numbers which determine the number of buses that PIEV groups should be connected to the smart distribution network at them. Candidate load points in the test system are just residential and commercial buses and the number of candidate load points does not exceed $2^{4}-1$, each chromosome for PIEV bus number is five bits so the population size is five. Other GA parameters, cross over fraction, mutation probability and population size set $0.65,0.18$ and 50 respectively [15]. The reliability-based objective function optimization is shown in Figure 4.

Particle swarm optimization (PSO) algorithm is introduced by Kennedy and Elberhart [16-18], supposed to be a optimization method based on the social behavior of flocks of birds. Optimization starts by generating random positions for particles. In order to avoid defined articles from leaving search space at the first iteration, these randomly-generated positions should be zero or a small value. Based on (5) and (6) standard version of PSO algorithm starts by generating random positions for the particles, within an initialization region. Velocities are usually initialized within that region, but they can also be initialized to zero or to small random values to prevent particles from leaving the search space during the first iterations. During the main loop of the algorithm, the velocities and positions of the particles are iteratively updated until a stopping criterion is met. The update rules are shown in (5) and (6).

$$
\begin{gathered}
V_{i}^{k+1}=w V_{i}^{k}+C_{1} \text { rand }_{1}+\left(\text { Pbest }_{i}^{k}-X_{i}^{k}\right) \\
+C_{2} \text { rand }_{2} \times\left(\text { Gbest }_{i}^{k}-X_{i}^{k}\right) \\
X_{i}^{k+1}=X_{i}^{k}+V_{i}^{k+1}
\end{gathered}
$$

where $X_{i}=\left[X_{i 1}, X_{i 2}, \ldots . ., X_{i d}\right]$ and $V_{i}=\left[V_{i 1}, V_{i 2}, \ldots ., V_{i d}\right]$ in are the position and velocity of the $i^{\text {th }}$ particle. Let Pbest $i=$ $\left[X_{i 1 p b e s t}, X_{i 2 p b e s t}, \ldots ., X_{i d p b e s t}\right]$ and Gbest $=\left[X_{1 g b e s t}, X_{2 g b e s t}, \ldots . . .\right.$, $\left.X_{d g b e s t}\right]$ be the best position of particle $i$ and its neighbors best position so far respectively. The key attractive feature of PSO is its simplicity as it involves only two models (5) and (6). 
$\omega=\omega_{\max }-\frac{\left(\omega_{\max }-\omega_{\min }\right) \text { iter }}{\text { iter }_{\max }}$

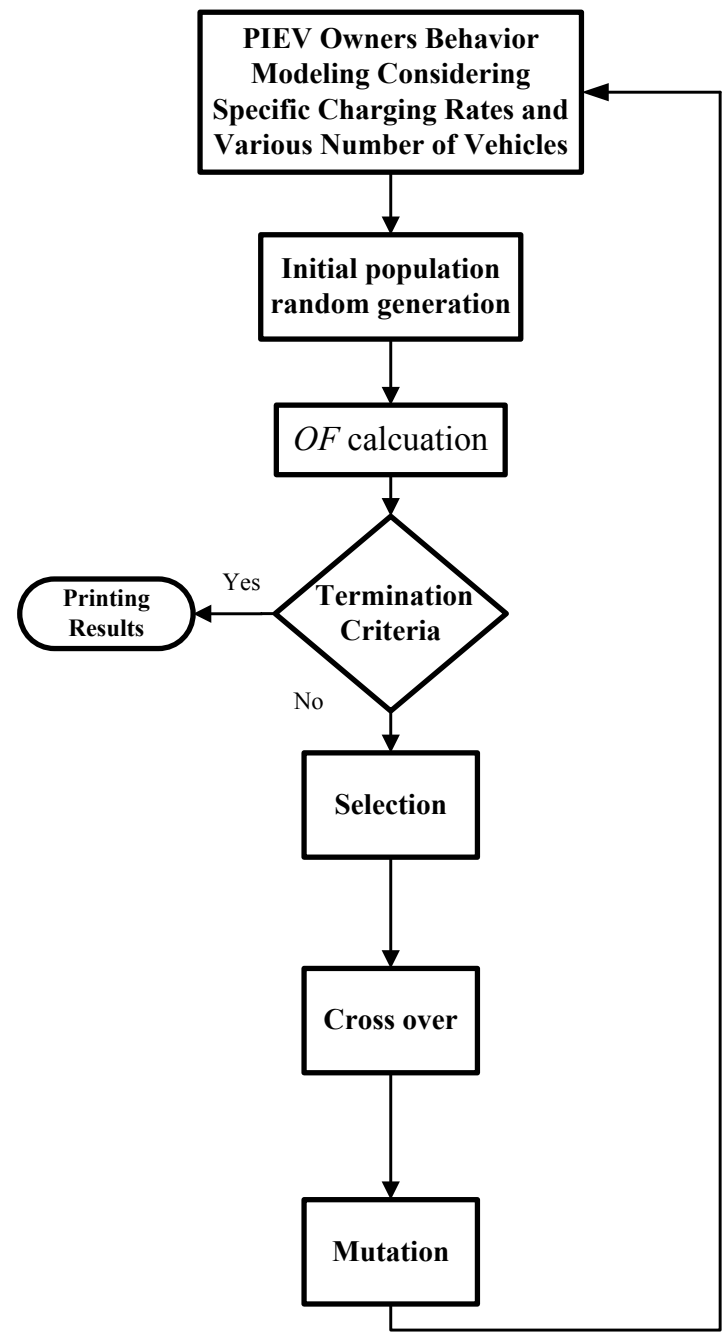

FIG. 4 OBJECTIVE FUNCTION OPTIMIZATION UTILIZINTG GENETIC ALGORITHM

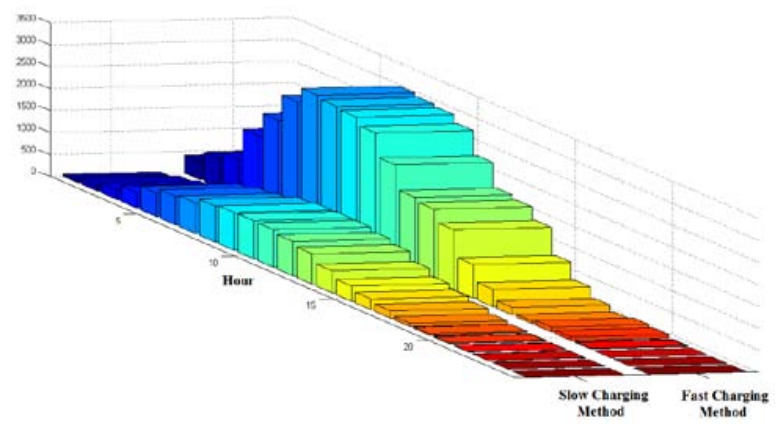

FIG. 5 COMPARING FAST AND SLOW CHARGING METHOD[10]

\section{Case Study}

Firstly, as it is mentioned in figure 5 the effect of charging rate is evaluated based on the PIEV model
[10]. In order to evaluate the proposed algorithm, it is tested on distribution system for RBTS [19][21]. This radial test system consists of four feeders with four types of customers, residential, commercial, government/institutions and small user that commercial and residential ones were considered as candidates for EVs' parking placement. The test system is shown in Figure 6. As a result, first and second feeders are connected as maneuver points with normally open switches. In addition, third and fourth feeders are also connected in the same way. The candidate buses do not include the exclusive industrial customers.

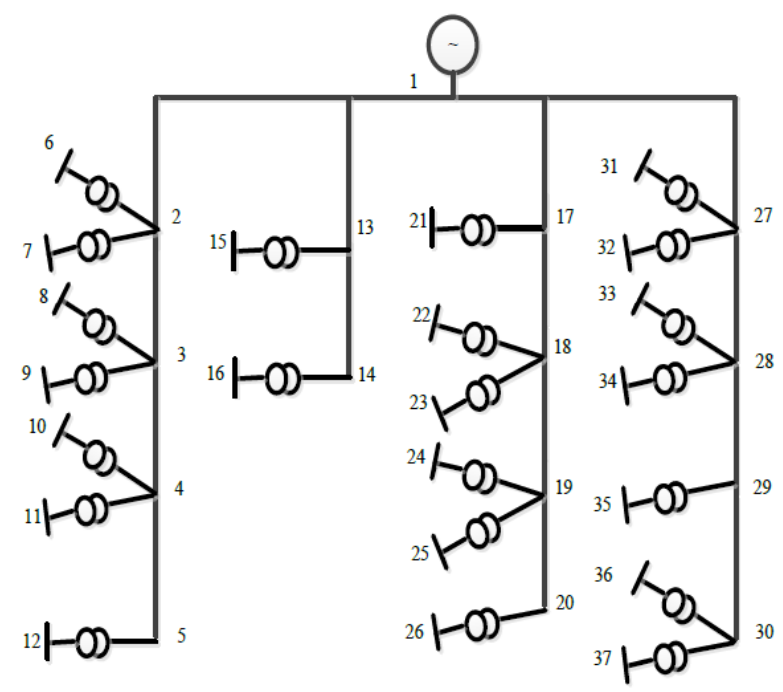

FIG. 6 DISTRIBUTION SYSTEM FOR RBTS BUS 2 [19]

\section{Simulation Results}

Four scenarios are defined to evaluate the effectiveness of the proposed method.

\section{Scenario 1}

In this scenario the slow charging method was considered. 1000 PIEVs considered to be allocated in five buses.

\section{Scenario 2}

In this scenario the fast charging method was considered. 1000 PIEVs considered to be allocated in five buses. The goal of defining this scenario is to evaluate the effect of charging rate on the proposed objective function and optimal placement of PIEVs.

\section{Scenario 3}

In this scenario the slow charging method was considered. 1500 PIEVs considered to be allocated in 
five buses.

\section{Scenario 4}

In this scenario the fast charging method was considered. 1500 PIEVs considered to be allocated in five buses. This scenario is defined to achieve a sensitivity analysis on charging rate effect on the value of proposed objective function.

Table II shows the results of optimization with GA and PSO. As the results shown, when the charging rate starts increasing, the OF value will reduce. For instance, the value of OF for fast charging is less than that of Slow and quick charging, considering the same number of PIEVs. Furthermore, a comparison between results of first and thirds scenario illustrates that when the number of PIEVs increased, OF value increased and this means the reliability will deteriorate by increasing PIEV number. Therefore, although the optimal allocation of PIEVs considering reliability indices improves reliability deterioration, high penetration of PIEVs reduce the level of reliability and in order to maintain an acceptable level of reliability, other smart equipments should be utilized at same time.

Figure 7 represents the value of proposed objective function using GA and PSO for introduced scenarios.
As results of this figure shows, particle swarm optimization is preferable for the reliability-based allocation of PIEVs and utilizing this optimization method leads to better reliability improvement.

\section{Conclusion and Future Work}

In this paper, a novel reliability-based placement of PIEVs utilizing two well-known heuristic optimization methods, GA and PSO, is introduced. The proposed method prevents future distribution network, called smart distribution network, from reliability deterioration after high penetration of PIEVs. Key feature of this approach is to consider two influential reliability indices simultaneously by defining a specific objective function. The case study results conclude that it is not feasible to connect PIEVs to industrial load points.

For the validation purpose, the proposed method has been implemented on distribution system for RBTS bus 2. The results of simulations show the high correlation of PIEV optimal location with charging method as well as total number of PIEVs (PIEV penetration). This paper analyzed the technical aspects of PIEV placement, including reliability features of distribution network. Future studied can concentrate on economical optimization of PIEVs' high penetration.

TABLE II SIMULATION RESULTS

\begin{tabular}{c|c|c|c|c|c} 
Scenario number & Charging Method & Total EVs & OF value (GA) & OF value (PSO) & $\begin{array}{c}\text { PIEVs' optimum } \\
\text { location }\end{array}$ \\
\hline WITHOUT EV & - & - & 1.05512 & 1.05512 & - \\
\hline 1 & SLOW & 1000 & 1.09134 & 1.08134 & $1,8,10-11,18$ \\
\hline 2 & FAST & 1000 & 1.06742 & 1.0731 & $2,12,16,18-19$ \\
\hline 3 & SLOW & 1500 & 1.11397 & 1.11237 & $1,6-7,17-18$ \\
\hline 4 & FAST & 1500 & 1.09981 & 1.0878 & $2,10,12,15,19$ \\
\hline 5 & QUICK & 1000 & 1.08136 & 1.08093 & $1,7,16,18-19$ \\
\hline 6 & QUICK & 1500 & 1.10072 & 1.09900 & $1,6,15,17,19$
\end{tabular}

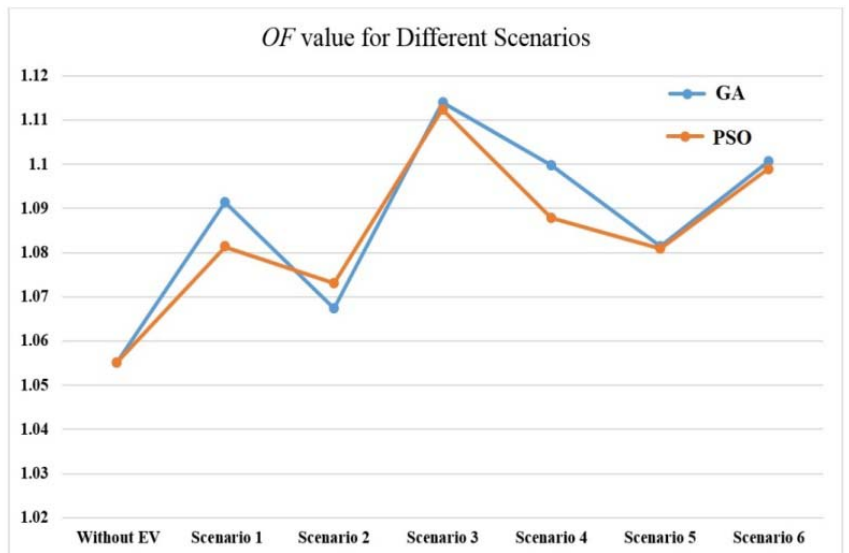




\section{REFERENCES}

Sargolzaei, Arman, Kang K. Yen, and M.N. Abdelghani. “Time-Delay Switch Attack on Load Frequency Control in Smart Grid." Advances in Communication Technology, Vol.5 (2013), 55-64.

Du Xin-Wei, Ye Qiang, 2005,"Review of Smart Grid and its Development Prospect in Sichuan, "IEEE power \& energy magazine.

Amin S.M., Bruce F.W., 2005, “Toward a smart grid," IEEE power \& energy magazine, vol. 34, No. 5, pp. 34-41.

F. Rahimi and A. Ipakchi, "Demand response as a market resource under the smart grid paradigm," IEEE Transactions on Smart Grid, vol. 1, no. 1, pp. 82-88, 2010.

Clark W. Gellings, “The Smart Grid: Enabling Energy Efficiency and Demand Response, " Published by The Fairmont Press, Inc, 2009.

Farhadi, M.; Mohammed, O., "Realtime Operation and Harmonic Analysis of Isolated and Non-Isolated Hybrid DC Microgrid," Industry Applications, IEEE Transactions on , vol.PP, no.99,pp.1,1. doi: 10.1109/TIA.2014.2298556.

Zahra Darabi, Mehdi Ferdowsi, "Aggregated Impact of Plugin Hybrid Electric Vehicles on Electricity Demand Profile", IEEE Trans. On sustainable energy, vol. 2, no. 4, Oct. 2011.

W. Kempton, and J. Tomic, "Vehicle to grid Implementation: from stabilizing the grid to supporting large-scale renewable energy," Journal of Power Sources, vol. 144, no.1, pp.280-294, Jun. 2005.

P. Mohseni, and R.G. Stevie, “Electric Vehicles: Holy Grail or Fool's Gold," IEEE General Meeting, Calgary, Alberta, Canada, 2009.

M.H. Amini, and M. Parsa Moghaddam. "Probabilistic modelling of electric vehicles' parking lots charging demand." Electrical Engineering (ICEE), 2013 21st Iranian Conference on. IEEE, 2013.

M.H. Amini, B. Nabi, M. Parsa Moghaddam and S.A. Mortazavi, " Evaluating the Effect of Demand Response Programs and Fuel Cost on PHEV Owners Behavior, A Mathematical Approach", Second Iranian Conference on Smart Grid, 2012.

R. E. Brown, Electric PowerDistribution Reliability. NewYork:Marcel Dekker, 2002.
L. Wang and C. Singh, "Reliability-constrained optimum placement of reclosers and distributed generators in distribution networks using an ant colony system algorithm ", IEEE Transaction on Systems, Man and Cybernetics-Part C: Applications and Reviews, vol. 38, No. 6, November 2008.

Moghadasi, A.H.; Heydari, H.; Farhadi, M., "Pareto Optimality for the Design of SMES Solenoid Coils Verified by Magnetic Field Analysis,"Applied Superconductivity, IEEE Transactions on, vol.21, no.1, pp.13,20, Feb. 2011.

Williams, E. A., and Crossley, W. A., "Empirically-Derived Population Size and Mutation Rate Guidelines for a Genetic Algorithm with Uniform Crossover," Soft Computing in Engineering Design and Manufacturing, P. K. Chawdhry, R. Roy and R. K. Pant (editors), SpringerVerlag, 1998, pp. 163-172.

J. Kennedy and R.C. Eberhart, Particle Swarm Optimization, Proceedings of the IEEE International Conference on Neural Networks, Vol.4, pp. 1942-1948, 1995

Kennedy, J. and Eberhart, R., Swarm Intelligence, Academic Press, 1st edition, San Diego, CA, 2001.

Eberhart, R. C. and Kennedy, J. A new optimizer using particle swarm theory. Proceedings of the Sixth International Symposium on Micromachine and Human Science, Nagoya, Japan. pp. 39-43, 1995

R.N.Allan, R.Billinton, I.Sjarief, L.Goel and K.S.So, “A reliability test system for educational purposes- basic distribution system data and results," IEEE Transactions on Power Systems, vo1.6, No. 2, May 1991.

Heydari, H.; Moghadasi, A.H., "Optimization Scheme in Combinatorial UPQC and SFCL Using Normalized Simulated Annealing," Power Delivery, IEEE Transactions on , vol.26, no.3, pp.1489,1498, July 2011.

M.H. Amini, B. Nabi and M. -R. Haghifam, “Load management using multi-agent systems in smart distribution network," IEEE PES General Meeting, Vancouver, BC, Canada, 2013.

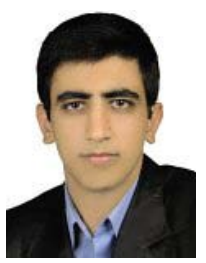

MohammadhadiAminiwas born in Shahreza. He received the B.S. and M.Sc. degree in electrical engineering from Sharif University of Technology and TarbiatModares University in 2011 and 2013, respectively. He is currently working 
toward the Ph.D. in electrical engineering at Florida International University. He has published more than 25 papers in Smart Grid Implementation field. His research interests include Smart Grid reliability assessment, real-time load estimation, smart grid mathematical modeling,plug-in electric vehicles, power system optimization and power system state estimation.

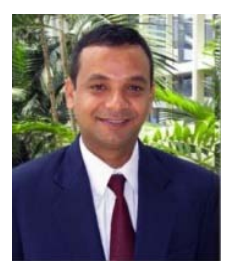

Arif I. Sarwatreceived his M.S. degree in electrical and computer engineering from University of Florida, Gainesville. In 2010 Dr. Sarwat received his Ph.D. degree in electrical engineering from the University of South Florida. He worked in the industry(SIEMENS) for nine years executing many critical projects. Before joining Florida
International University as Assistant Professor, he was Assistant Professor of Electrical Engineering at the University at Buffalo, the State University of New York (SUNY) and the Deputy Director of the Power Center for Utility Explorations. He is co-developer of the DOE funded Gateway to Power (G2P) Project along with FPL/NextEra company. His significant work in energy storage, microgrid and DSM is demonstrated by Sustainable Electric Energy Delivery Systems in Florida. $\mathrm{He}$ is also co-principle investigator in the study of reliability \& predictability of high penetration renewable resources power plants (DOE) funded Sunshine State Solar Grid Initiative (SUNGRIN). His research areas are Smart Grids, High Penetration Renewable Systems, Power System Reliability, Large Scale Distributed Generation Integration, Large Scale Data Analysis, Distributed Power Systems, and Demand Side Management. 